\title{
ALBACETENSES EN RUSIA, 1941-42: UNA ORLA DEL PRIMER CONTINGENTE DE LA DEV (LA «DIVISIÓN AZUL»)
}

\section{ALBACETENSES IN RUSSIA, 1941-42: A PROM PICTURE OF THE FIRST CONTINGENT OF THE DEV (THE "BLUE DIVISION")}

\author{
Aurelio Pretel Marín \\ Instituto de Estudios Albacetenses «Don Juan Manuel» \\ Albacete, España \\ apretelmarin@gmail.com
}

Cómo citar este artículo: Pretel Marín, A. (2021). Albacetenses en Rusia, 194142: una orla del primer contingente de la DEV (la «División Azul»). Al-Basit (66), 301-331. http://doi.org/10.37927/al-basit.66_8

Recibido/Received: 14-05-2021

Aceptado/Accepted: 01-07-2021

RESUMEN: Un documento inédito, que presenta las fotos de 120 voluntarios del primer contingente que Albacete envió a Rusia en 1941, y regresaron en 1942, es la base de un pequeño estudio que pretende explicar sus motivos para ir y la ausencia de algunos muy significativos.

PALABRAS CLAVE: Albacete. II Guerra Mundial. División Azul. Rusia.

\begin{abstract}
An unpublished document, which presents the photos of 120 volunteers from the first contingent that Albacete sent to Russia in 1941, and they returned in 1942, is the basis of a small study that aims to explain their reasons for going and the absence of some very significant ones.
\end{abstract}

KEYWORDS: Albacete. II Guerra Mundial. División Azul. Rusia.

Hace poco cayó, por azar, en mis manos, una curiosa orla que los albacetenses del primer contingente de la DEV o División Española de Voluntarios, mucho más conocida por el nombre de División Azul con que los falangistas consiguieron patrimonializarla, y en Alemania como 205 División de la Wehrmacht, o 250 Spanien Division (lo de Blau División es un contagio del nombre en español), hicieron al regreso de las estepas rusas, en recuerdo honorífico de su 
experiencia bélica. Como tal documento, no es ningún prodigio de objetividad ni exactitud histórica, puesto que no están todos, como podremos ver; y tampoco parece excepcional o único, porque luego he sabido que quedan otras copias en el mismo Albacete, y que los hay también bastante semejantes de otras localidades y provincias de España. Sin embargo, contiene bastante información, hasta el momento inédita, sobre el nombre, el primer apellido y el aspecto de los divisionarios... Y algún que otro enigma, que intentaré aclarar -o, por lo menos, poner de manifiesto- consultando otras fuentes y abusando de la amabilidad de don Raúl Rodríguez, secretario actual de la Hermandad, y de Amador Rodríguez, igualmente sobrino del que fue presidente, a los que he de empezar reconociendo su paciencia y ayuda y las ilustraciones que me han proporcionado.

La orla es un rectángulo de 74 X $52 \mathrm{~cm}$. recorrido en su parte superior por una filacteria o cinta rojigualda que lleva una inscripción grandilocuente, racista y fanfarrona: «Duro es el enemigo y muy duro el invierno ruso, pero no importa: más dura es mi raza. Muñoz Grande» (se refiere, obviamente, al general Agustín Muñoz Grandes). Debajo hay una fila de honor de nueve fotos, entre el escudo propio de aquella División y el águila germana con la esvástica (por cierto, del revés), en la que están aquellos que ostentaban cargos en el Partido o las instituciones, presididos por el gobernador y jefe provincial de FET y de las JONS, Ramón Laporta (que también se alistó, aunque pronto encontró responsabilidades más urgentes que la de ir a Rusia), junto a Pedro Lamata, Ricardo Acebal, Manuel de Luna Barrios, José de Luna Cañizares, Enrique Serra, Juan Pedro Fernández, Francisco Soriano y Ramón Aguilar, delegado del SEU (los dos últimos volvieron mutilados). Más abajo, otras 100 fotografías rodeando a los nueve caídos en campaña: Dionisio Acebal, Luis Badía, José García y Cándido García, José González, Enrique Jiménez, Manuel Flores (que en realidad murió al volver a Albacete, el 16 de abril) y Federico Martínez (que es Martínez-Falero, cuya muerte se supo en la ciudad a mediados de junio, lo que permitiría fechar el documento después de dicho mes y antes del de julio, cuando la re- 
lación alcanza ya los 13), que rodean a su vez a la Patrona, la Virgen de los Llanos. Faltan cuatro difuntos -que debieran ser cinco, por lo menos- cuyos nombres figuran junto a estos en la esquela que publica el periódico Albacete del día 2 de julio (Agustín López, Vicente Sánchez, Antonio Landete, Ricardo López Sánchez y cierto Gaspar Pérez, que es una confusión). Estos 100, o 101, están distribuidos en un par de columnas laterales de a 42 fotografías y 17 más en la parte inferior. En total, 110 divisionarios vivos, incluido Laporta, que se enroló y no fue, y Lamata, que había sido el único gestor municipal que se alistó en respuesta a la convocatoria, más los 8 difuntos mencionados, casi todos vestidos de uniforme alemán, algunos con la boina o el gorro falangista, y alguno de paisano.

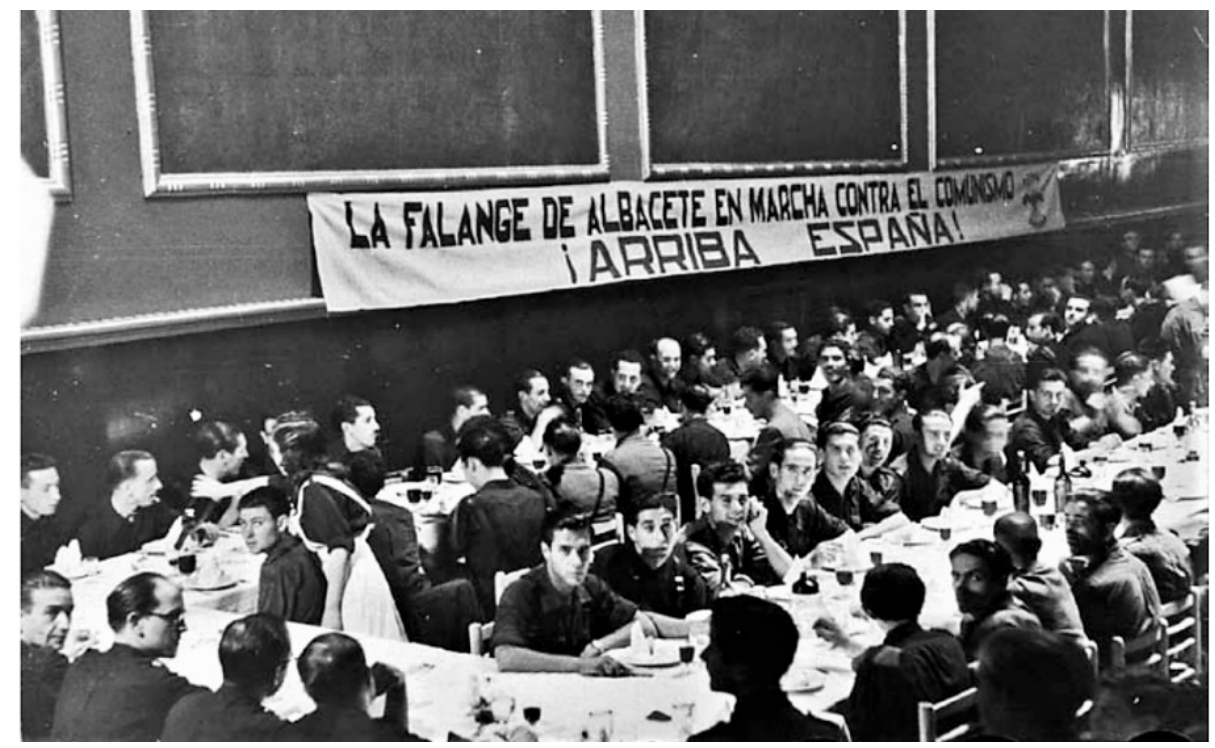

Homenaje a los que iban a salir para Rusia, en el «Hogar José Antonio» de Albacete, el 28 de junio de 1941. 


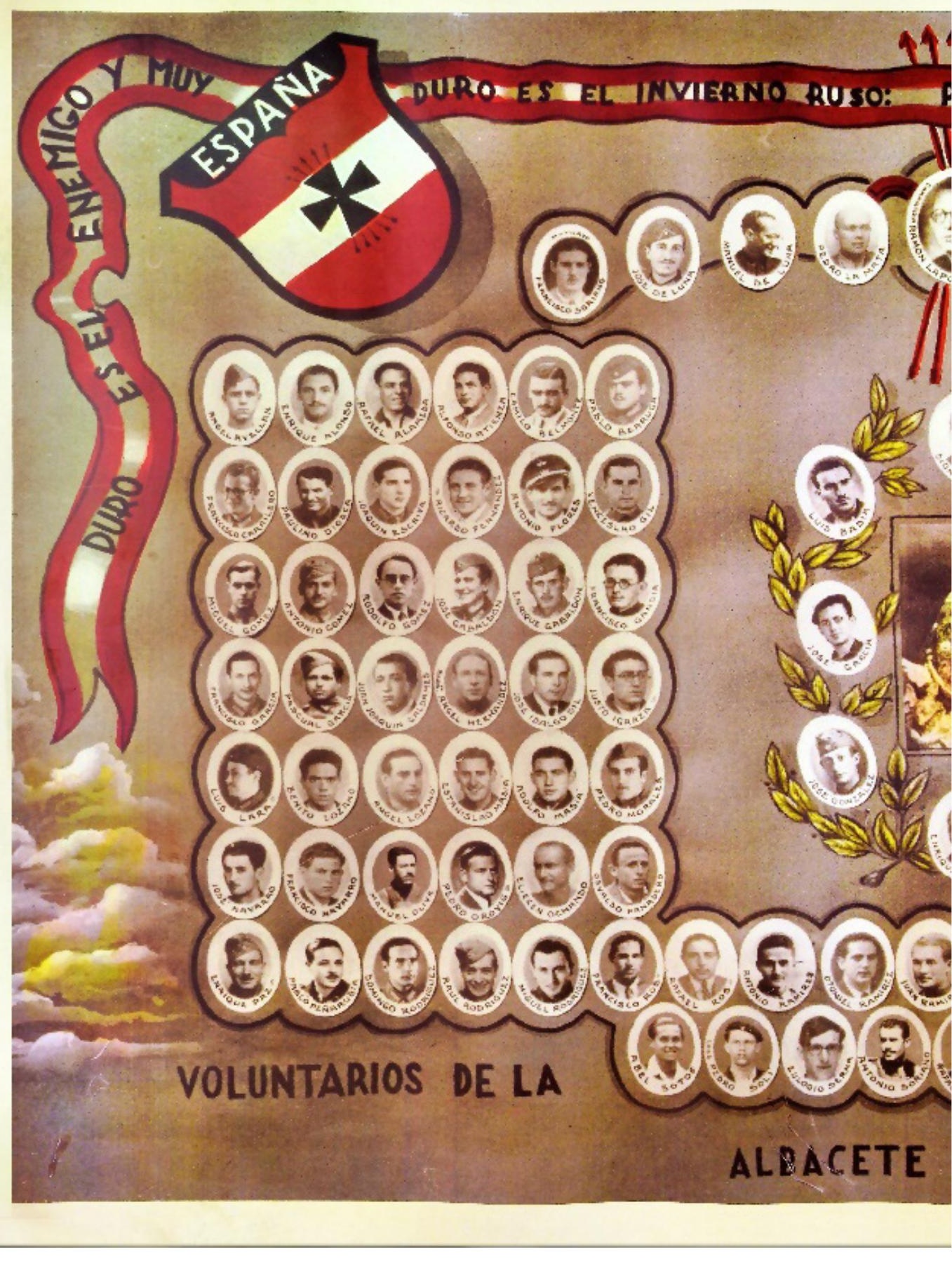



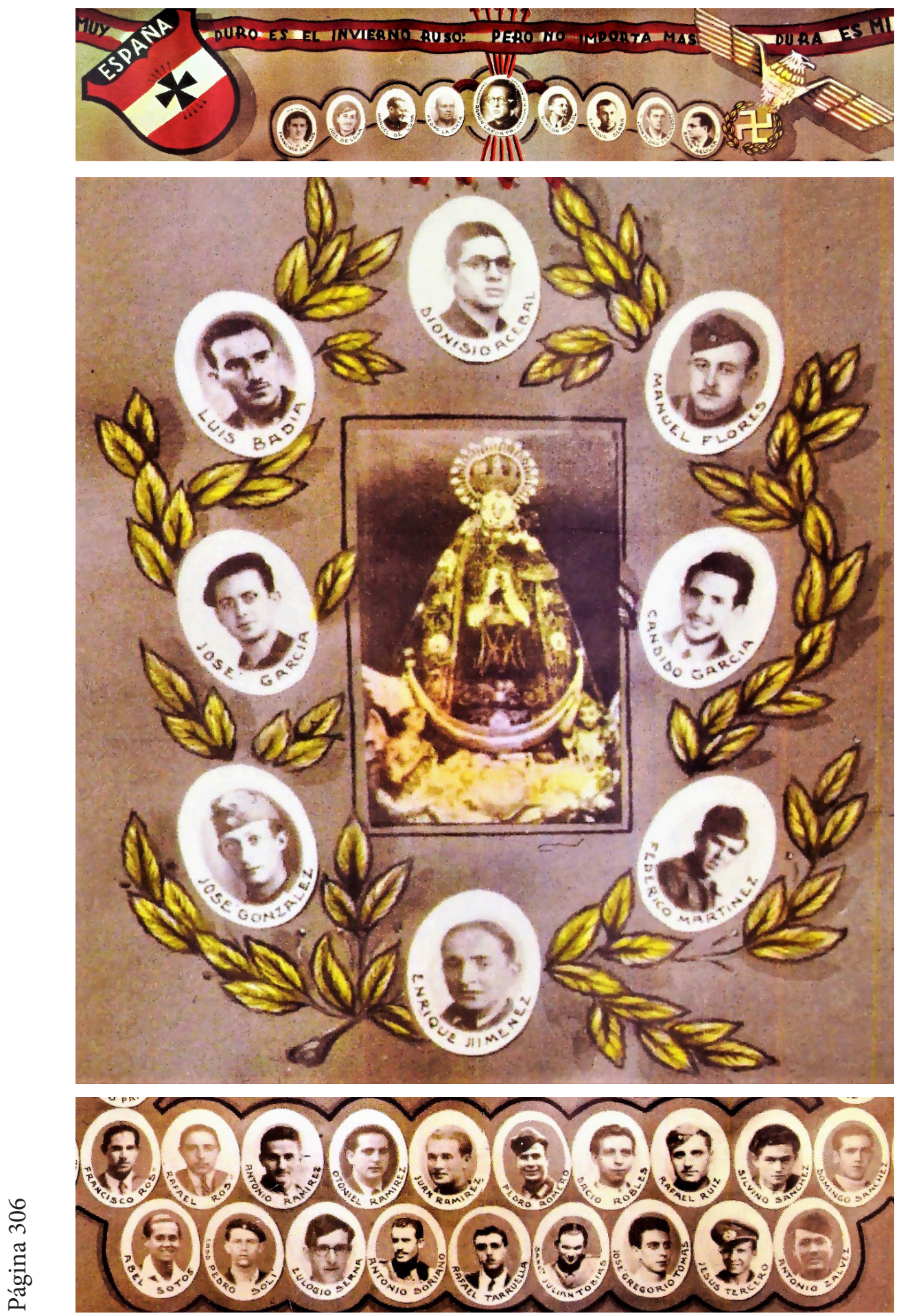


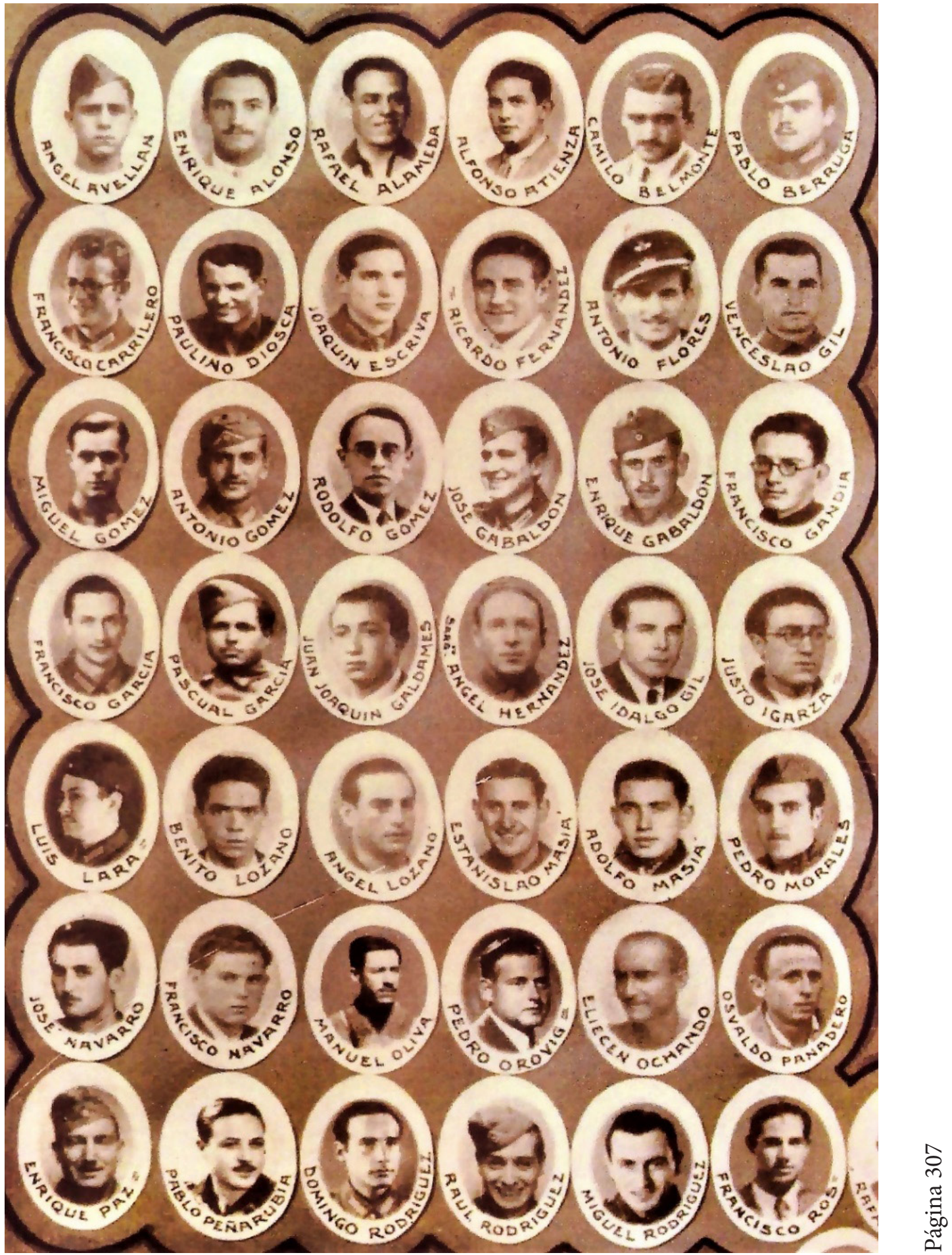




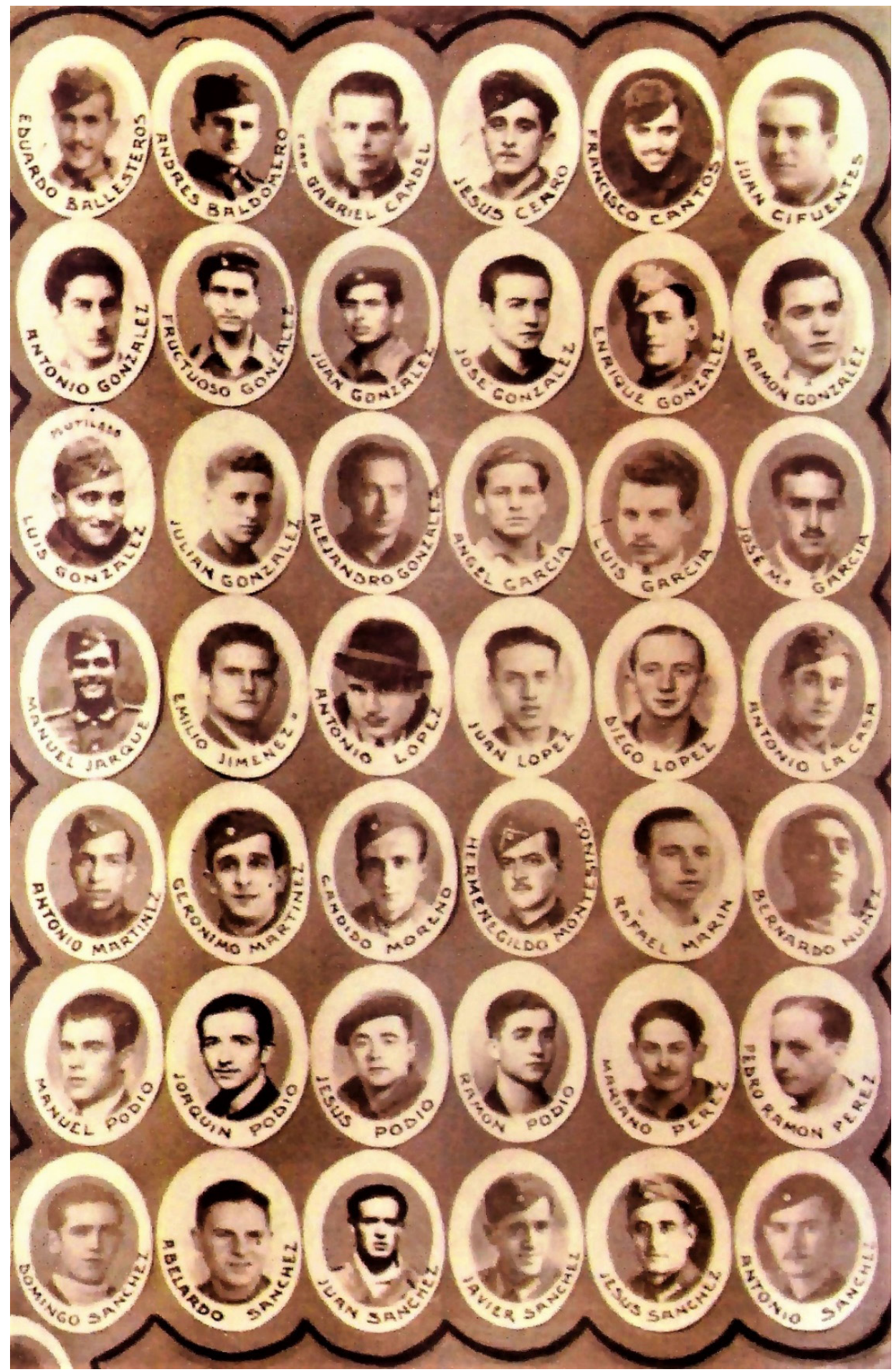


Como ya queda dicho, en la orla hay 110 fotografías de voluntarios vivos y de ocho caídos, que debieran ser 9, a los cuales habría que sumar los cinco que se añaden en la esquela de julio. Por tanto, conocemos el nombre y el primer apellido de por lo menos 124 soldados del primer contingente que salió de nuestra capital a principios de julio de 1941; es decir, la mitad, o poco menos, de los 275 hombres de toda la provincia -de casi 1.000 inscritos- que Alcalde ha calculado partieron desde ella para Rusia (según el presidente de la Hermandad, Romera, de 540 voluntarios llegaron a Valencia 350; que serían 329 para el autor citado, aunque fueron devueltos a Albacete 54 de ellos). A excepción de Laporta, que está en razón del cargo y en el pobre papel de «capitán Araña», son todos los que están, y en cambio no figuran algunos que estuvieron, e incluso perecieron, en la campaña rusa, como Pedro Ramírez Gutiérrez, del que no hay noticia, quizá porque se hubieran enterrado sus restos con nombre equivocado, como podremos ver..., y ciertos personajes muy significativos, de los que en su momento volveremos a hablar. En todo caso, ellos fueron los que llevaron la sangre de Albacete (mejor dicho, de parte de Albacete) a las estepas rusas en aquella aventura que para algunos fue una continuación de la Guerra Civil e incluso una cruzada movida por el odio al comunismo ruso, aunque es obvio que este no era responsable no solamente ya de la guerra de España, pese a lo que dijera Ramón Serrano Suñer, sino de la Mundial (recordemos que esta comienza tras el pacto Von Ribbentrop-Molotov y el reparto entre ambos de Polonia, en agosto de 1939, y que el entendimiento entre Stalin y Hitler no se rompe hasta junio de 1941, con la agresión de aquel contra la Unión Soviética).

Propagandas aparte, la auténtica razón de su presencia en Rusia era más complicada y no se debe solo al anticomunismo: aunque no se atrevía a provocar a Churchill y a los americanos (que podían tomar fácilmente Canarias e invadir la Península), el tortuoso Franco seguía manteniendo su «no beligerancia» y su oferta de entrar en la contienda contra los aliados si Alemania le hacía algunas concesiones, que para Hitler eran gravosas e imposibles. En medio, 
el «cuñadísimo» y ministro Ramón Serrano Suñer, partidario del Eje, no lograba el acuerdo: habían fracasado la entrevista de Hendaya, el proyecto de ataque a Gibraltar y el intento final de Bordighera; pero con la invasión de Rusia por los nazis, el 22 de junio de 1941, volvía renacer una oportunidad de contentar al Führer y recobrar poder frente a los militares -sobre todo, el general Varela, sobornado por Churchill, aliadófilo y opuesto al totalitarismo de Falange Españolay otros competidores dentro del Movimiento. Solo dos días después de la invasión de Rusia, Serrano declaró que esta era culpable de la Guerra Civil y de la muerte del mártir José Antonio (que murió en Alicante, no en Moscú, y sentenciado por un tribunal español), y dejó bien patente su intención de luchar «junto a las mejores tropas del mundo», para «contribuir en la fundación de la unidad de Europa». Se supone, obviamente, que una Europa gobernada por Hitler, competidor de Stalin por el título de mayor asesino de la Historia de este continente, al que los voluntarios juraron lealtad en Grafenwöhr, en agosto de 1941, cuando ya parecía que el ejército ruso estaba derrotado. Por su parte, el Caudillo dejaría bien claro que aquellas «democracias plutocráticas», irían al desastre por aliarse al «criminal dictador» Stalin, lo que las enfrentaba a «nuestros camaradas del Eje», a los que iba a unirse la juventud de España, como han visto Suárez Fernández y Preston desde sus diferentes perspectivas. Esto provocaría advertencias británicas, movimientos de alerta entre los generales españoles, que en agosto enviaron a Orgaz y Aranda -sobornados también por los ingleses- al palacio de El Pardo, como señala Preston, e impusieron un nuevo frenazo en el proceso de incorporación a la Guerra Mundial; pero, en tanto, Serrano había conseguido tener la iniciativa y meter en la misma a miles de españoles. Si estos eran conscientes o no de las razones por las que iban a Rusia es pregunta que tiene mil posibles respuestas, casi tantas como divisionarios.

Desde luego, parece que la gran mayoría de los jóvenes que salieron en julio de 1941 de la antigua estación albacetense, al engañoso grito de «Rusia es culpable», eran ya «falangistas», aunque 
esto no dice demasiado, pues entonces se entendía por tales no solo a los fascistas de la antigua Falange Española y de las JONS, sino a conservadores y nacionalcatólicos confundidos con ellos en el cajón de sastre de FET y de Las JONS, fusión artificial de distintas tendencias reaccionarias y revolucionarias, donde prácticamente cabía todo el mundo, incluidos no pocos anarquistas, que pasaron de la CNT a la CNS y se aferraron con fuerza al «salvavidas», como algunos llamaban a la camisa azul. Entre los de Albacete no encontraremos hijos de las familias ricas de antes de la Guerra que se beneficiaron del triunfo del franquismo (solo hay un Legorburo, de segundo apellido). En cambio, sí veremos algún «camisa vieja» (pocos, porque jamás habían sido muchos, y bastantes habían sucumbido tras fracasar el golpe del año 36, sin contar con que ya no estaban en edad), algunos filonazis y muchachos recién incorporados al nuevo Movimiento, chicos de clase media deseosos de gloria, estudiantes y maestros (se ha dicho que el nivel cultural era muy superior al de otras unidades, pero aquí solamente sabemos de unos cuantos), e incluso algún que otro médico o abogado que ya sobrepasaban la edad de alistamiento, pero habían de limpiar su ejecutoria o la de sus parientes. Junto a ellos, devotos de la Virgen de los Llanos, antiguos dirigentes de la Federación de Estudiantes Católicos, y ahora del SEU falangista, como Aguilar Granados..., e incluso algún agnóstico, como parece ser Martínez de la Ossa, que además tenía antecedentes poco recomendables desde el punto de vista falangista. Y es de suponer que, como en toda España, personas sin trabajo, exmilitares del bando equivocado, algún ladrón vulgar que huía de los jueces, algún «indeseable» de aquellos que Laporta había detectado un par de años antes entre los militantes de Falange de toda la provincia... Pero la mayoría nunca habló ni escribió, y es difícil juzgar por las palabras de los pocos que lo hacen.

Desde luego, no es fácil resumir la casuística, y tan falso sería decir que todos eran fervientes filonazis como que eran pobres muchachos engañados por una propaganda religiosa y patriótica exaltada, que rezuma en las crónicas y escritos que enviaban desde 
el frente, fiel reflejo de aquella. Sin duda, sobre todo en los primeros tiempos, dominan las ideas falangistas, católicas o de extrema derecha, que son muy diferentes, pero tienden a unirse en la posguerra dentro del Movimiento, de quienes no llegaron a conocer el frente, pero participaron en el golpe de 1936 -como hicieron Remigio Martínez Espinosa y su padre, o Ricardo Acebal, hijo de un magistrado que dice haber sufrido persecución política- y quedaron con ganas de aventura después de la contienda. Otros, también muy jóvenes, como Sánchez Carrilero, ya habían realizado en 1937, con 18 años, reuniones clandestinas en su casa y en la imprenta Collado con Carlos y Manuel Belmonte, Atanasio Orovigt y otros sospechosos, según Asensio Puche, el policía que les siguió la pista (fusilado, por cierto, en abril del 39); y después de la guerra muchos de ellos se afiliaron gustosos a FET y de las JONS.

Otros, habían pasado por las cárceles «rojas» -más bien, republicanas-, como Pedro Lamata, por su actuación en julio de 1936, y otros se verían impulsados, como Serna y Podio, por el rencor a aquellos que habían asesinado o fusilado por sentencia legal a parientes cercanos a raíz del fracaso del golpe militar. 0 , todo lo contrario, querían lavar culpas familiares o propias: los hermanos Belmonte, por ejemplo, eran hijos de un conocido líder republicano; los Ramírez de Lucas, Juan y Antonio, tenían a su hermano mayor en el exilio, aunque el primero de ellos, que además fue amante del poeta García Lorca, fusilado en Granada, suele manifestarse como un falangista convencido. Otros, sencillamente, se dejaron llevar por una propaganda épica fomentada por los medios de comunicación, o bien por las promesas de mejora social o laboral que se les ofrecían: doble paga, alemana y española, dispensa de derechos y tasas académicas y prioridad en las oposiciones al cuerpo de maestros o al de policía, por no hablar de la administración local o de los sindicatos, y abono de una parte de su sueldo, hasta que regresaran, a los trabajadores de la Diputación. 


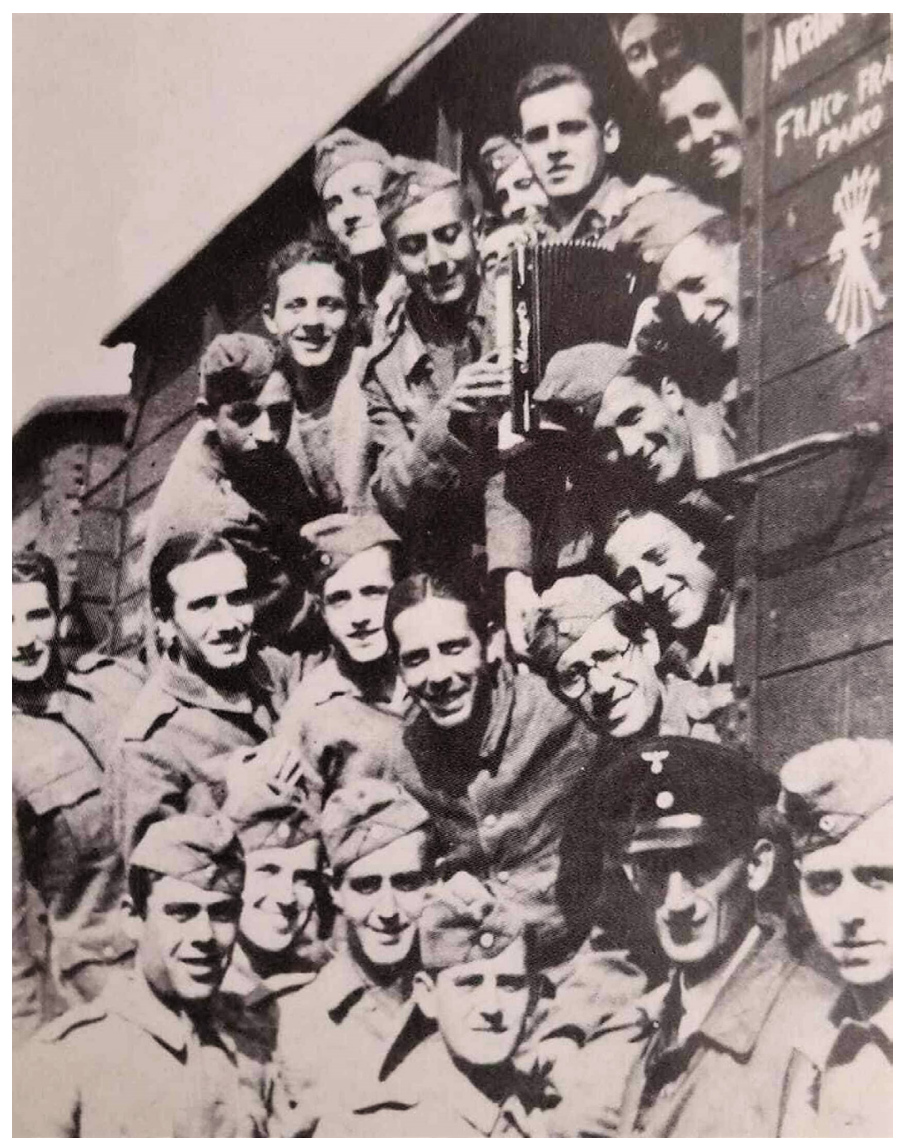

La «alegre muchachada» en camino hacia Rusia.

Una vez enrolados, aquellos voluntarios cumplieron su deber con mayor o menor arrojo y entusiasmo, e incluso se ganaron, según dicen algunos, el aplauso alemán y el respeto enemigo, aunque la mayoría no cuenta su experiencia ni escribe en los periódicos. Sí lo hacen, en cambio, Juan Ramírez de Lucas, Rafael Prieto Alarcón, Raúl Rodríguez, Luis Martínez de la Ossa, José de Luna Cañizares y Sánchez Carrilero, que enviaron sus crónicas, henchidas de fervor religioso y patriótico, de odio al comunismo, al que la propaganda hacía responsable de los males de España, y de admiración hacia el pueblo alemán (y hacia sus dirigentes, aunque que el último de ellos niegue tal simpatía cuando en 1992 recopila las suyas en un libro). Incluso de desprecio, no exento de amenazas, hacia los «señoritos» 
que se habían quedado en Albacete esperando el final de la contienda.

Entre los voluntarios hubo ideas distintas, pero todos lucharon, y algunos se dejaron la vida en las estepas, empezando por Dionisio Acebal, enterrado el 30 noviembre de 1941, y Luis Badía, en diciembre, abatidos los dos por francotiradores, o Cándido García, cuyo recordatorio dice que falleció el 19 de enero, con 20 años, y sabemos que fue enterrado el 10 de febrero, aunque un compañero, entrevistado en La Voz de Albacete, informa de su muerte a causa de un obús que cayó en su trinchera y exagera diciendo que tardaron tres meses en hacerlo porque había más de un metro de nieve congelada. Más o menos entonces cayó Pedro Ramírez Gutiérrez, al que no se menciona ni en el cuadro de honor ni en las esquelas, quizá porque en su tumba, que se ve en primer término en una de las fotos que trajeron a España sus paisanos, aparece, sin duda por error, bajo el nombre de Pedro Romero -no Ramírez- Gutierrez (aunque hay otro Pedro Romero que sí volvió de Rusia, pues figura en la orla con su gorro y guerrera alemana). Lo curioso del caso es que los familiares de Ramírez, tal vez por ignorar la fecha de su muerte y no tener acceso a otra imagen de él vestido de uniforme, usaron el de Cándido, cambiándole los nombres y borrando los ojos del difunto.
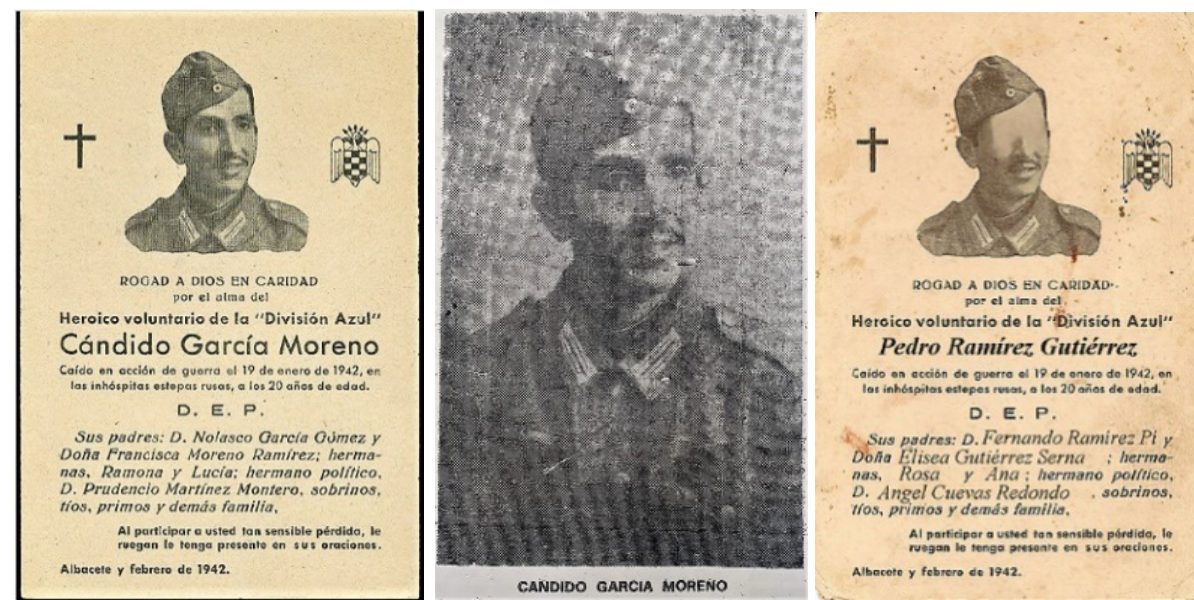

Recordatorio auténtico de Cándido García, con la foto aportada por su amiga Encarnita Martínez a La Voz de Albacete el 22 de julio de 1980. A la derecha vemos el de Pedro Ramírez (no Romero). 

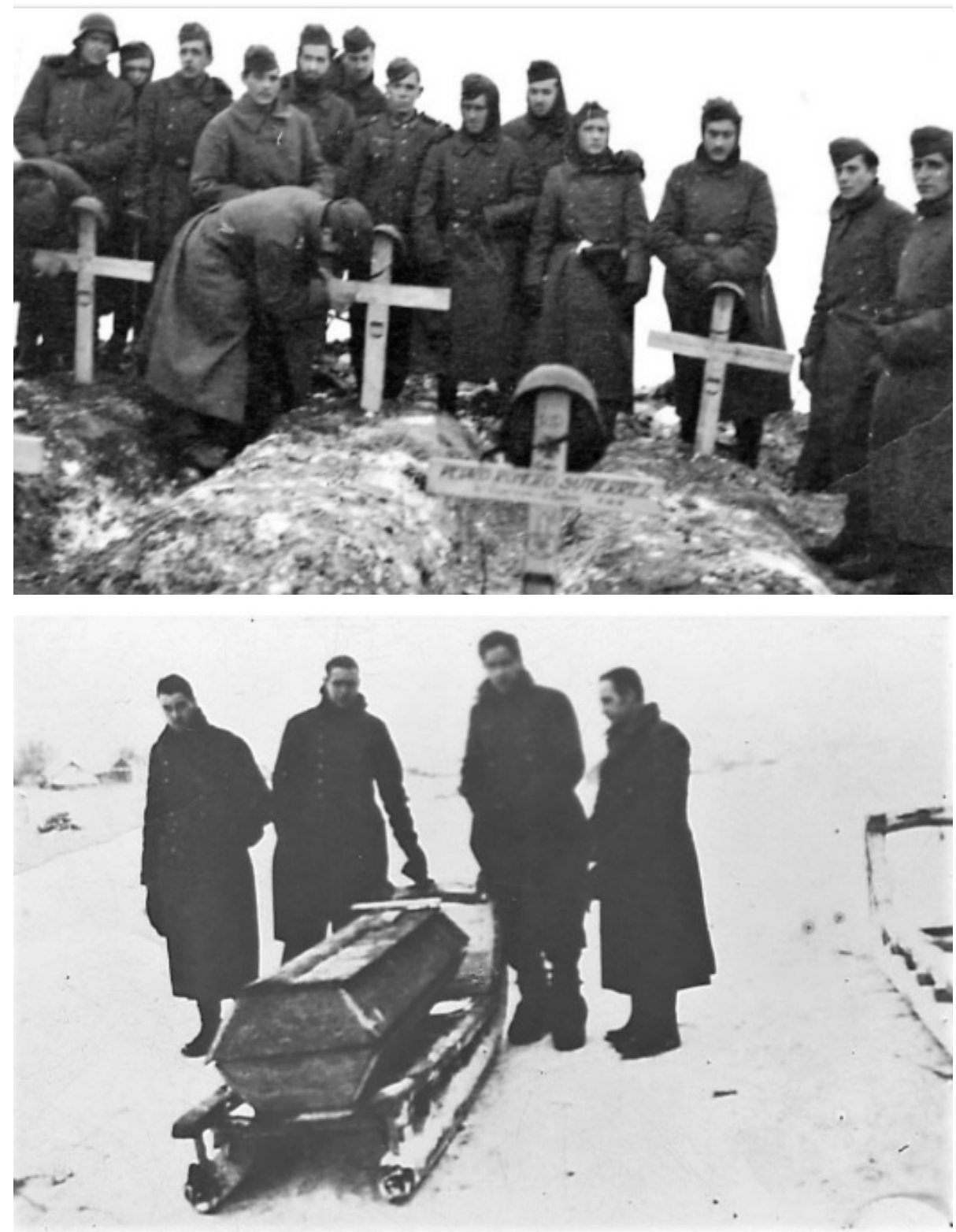

Cementerio español. En primer término, la tumba de Pedro Romero Gutiérrez. Traslado del cadáver de Cándido García para su inhumación.

Pronto comenzarían a llegar a Albacete los enfermos y heridos (por lo menos, Jerónimo Martínez y José Gabaldón), y los nombres de los divisionarios que ya no volverían: como ya señalamos, en 
la esquela que publica el periódico local del día 5 de mayo de 1942 aparecían siete de los ocho caídos de la orla, aunque faltan en ella Manuel Flores, que había fallecido en Albacete el 16 de abril, y Federico Martínez-Falero, cuya muerte se supo a mediados de junio. En cambio, no encontramos en la orla a Gaspar García Quintanilla, que sí figura en ella, y que reaparece en la esquela de julio como Gaspar Pérez Quintanilla, junto con otros nuevos: Ricardo López Sánchez, Antonio Landete, Vicente Sánchez y Agustín López Montero, hasta un total de trece. Esta falta absoluta de rigor en los datos, y la falta de otros, como Pedro Ramírez, ya citado, pueden dar una idea de la improvisación con que se realizaron la movilización o la repatriación. En febrero, no obstante, se habían publicado unos versos que envía desde Rusia Juan Ramírez de Lucas a Cándido García, su camarada muerto, y una sentida crónica de Sánchez Carrilero hablando de Ramón Aguilar, de las heridas que ha sufrido en el frente, deseando volver a cantar juntos el Cara al Sol al cielo claro de la patria, y del fallecimiento de Cándido García y Enrique Jiménez. No faltaran menciones y recuerdos más o menos cargados de lirismo y emoción religiosa y patriótica, que cruzarán Europa en ambas direcciones, aunque algunos tendrán que conformarse con mandar sus saludos y noticias sobre su buen estado de salud por la radio, como Pedro Jiménez y Antonio Vallescó (que, por cierto, después no salen en la orla, ignoramos por qué).

Alguna vez hallamos visiones enfrentadas sobre el significado de la Guerra Civil, del Movimiento y de la División: el día 3 de marzo se había publicado un artículo crítico de José de Luna Cañizares, un maestro interino de los de la República, que, al alistarse en julio, no pudo presentarse a las oposiciones de maestros de agosto de 1941, para las que ya en marzo había presentado méritos preferentes como hijo de muerto por los «rojos» y como excombatiente (lo cual quiere decir que se habría pasado al otro bando desde el republicano, en el que fue llamado a filas el 1937). Este divisionario, que sin duda sería de los pocos que habían combatido en las filas franquistas, y es de suponer que se hubiera afiliado a Falan- 
ge durante la contienda, gozaba, al parecer, de cierta autoridad (de hecho, en la orla ocupa un lugar relevante). En su crónica, en línea radical hedillista, cargará contra aquellos «reptiles despreciables», «señoritos», «caciques sempiternos», que en la Guerra Civil se refugiaron en sus cotos de caza o en el extranjero, en lugar de marcharse a combatir al frente -solamente le falta ponerse como ejemplo- $y$ ahora estorban la marcha de la revolución nacional-sindicalista y pretenden seguir explotando al obrero y usando su dinero de escabel para sus ilegítimas ambiciones políticas (un dardo dirigido contra terratenientes como Manuel Lodares, que hasta poco antes fue alcalde de Albacete, con su camisa azul, pero fue forzado a dimitir por el gobernador, y quién sabe si no contra algún otro miembro de su propio partido). Otros, en cambio, pintan un Albacete idílico, como hace Javier Sánchez Carrilero, que se escandaliza ante la falta de libertades públicas y las deportaciones o el terror que sufrían los ciudadanos rusos, viviendo «en casas grises que semejan hormigueros humanos» o «barracas de madera sucias y malolientes»; como si en su ciudad no hubiera paredones, cárceles y chabolas, ni personas viviendo «en la más lamentable miseria física y económica..., en chozas, cabañas o cuevas inmundas, como en los buenos tiempos prehistóricos», como reconocía poco antes el primer gobernador franquista, Parellada García.

Desde mayo comienzan a llegar grupos de repatriados, recibidos como héroes, cosa que se comprende, y ¡como vencedores!, cosa más discutible. En el primero llegan, entre otros, Domingo Rodríguez Romera, Manuel Podio, Ricardo Acebal, Estanislao Masiá, Rafael Fernández López y Luis Martínez de la Ossa, quien el 11 de junio se descuelga, en el diario Albacete, escribiendo un artículo lleno de admiración al pueblo y al ejército alemán, en el que trata a Hitler de «genio universal que imbuyó a la gran tabla de logaritmos que es su ejército el espíritu del gran pueblo alemán», y recuerda de paso que «la vida es milicia», como ya decía José Antonio, tanto para los que quedaron en Rusia combatiendo como para el conjunto de civiles que están en Albacete. Pocos días después llegará la se- 
gunda expedición, con José Belmonte González y Remigio Martínez Espinosa, y después José Saus, Manuel Luna, Antonio Cuerda, Pablo Berruga y Gonzalo Botija, entre otros de toda la provincia, y Rafael Tarruella, que sabemos llegó por esas fechas, aunque no es mencionado. Todos ellos serían recibidos por la banda de música con interpretación del Himno Nacional y una salve a la Virgen de los Llanos, y por Ramón Laporta, gobernador y jefe provincial, que también era divisionario, aunque no practicante), y con ellos vendrían las nuevas, por ejemplo, de las muertes de Antonio Landete, de Valdeganga, y Federico Martínez-Falero, de Albacete. El 2 de julio el único diario provincial publicaba la esquela de los 13 caídos de Albacete que se han quedado en Rusia, flanqueada por un verso de Ramón Aguilar y un artículo -el último- de Sánchez Carrilero, titulado «Promesa cumplida».
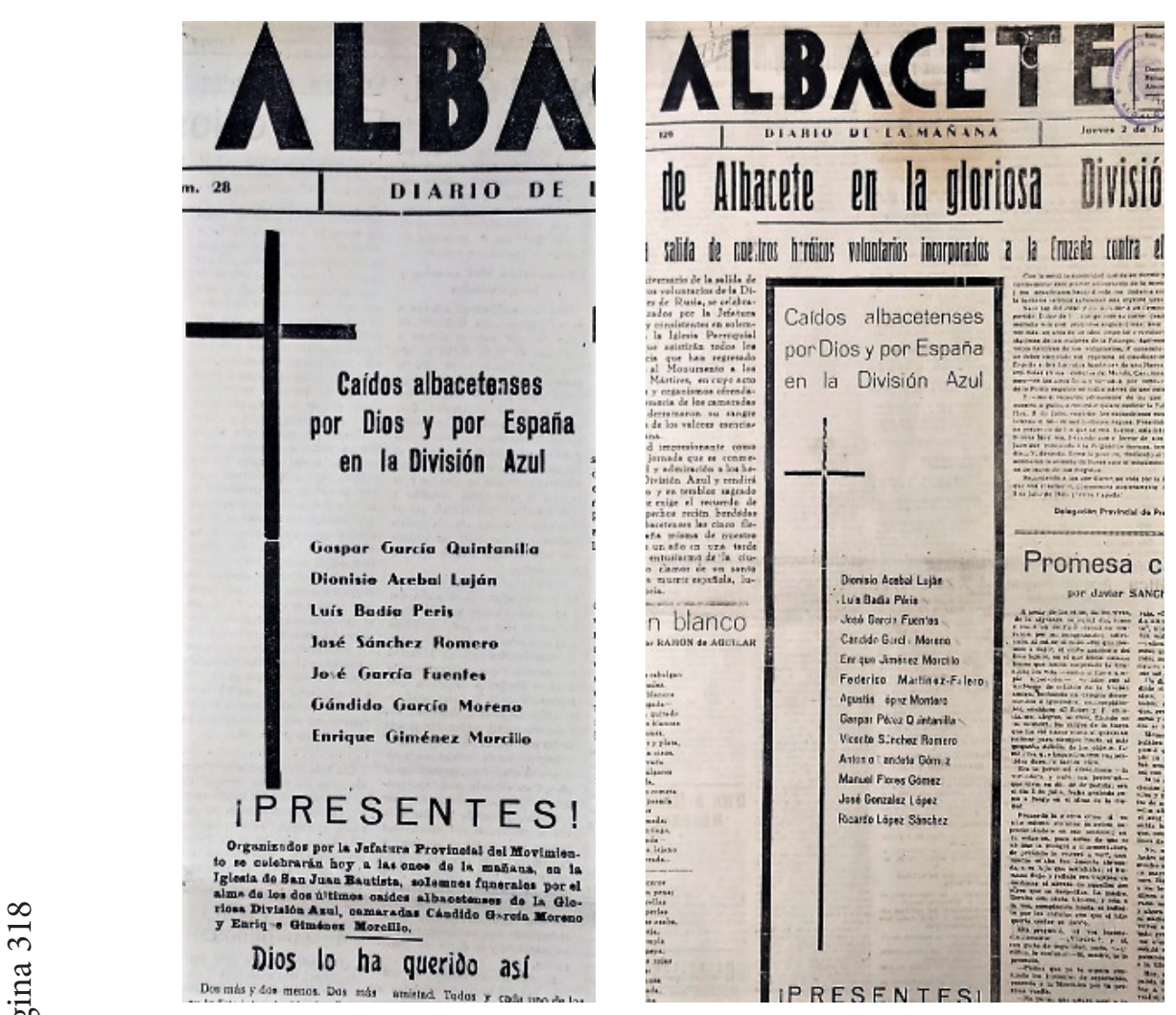

Esquelas de caídos en el diario Albacete de 5 de mayo y 2 de julio. 


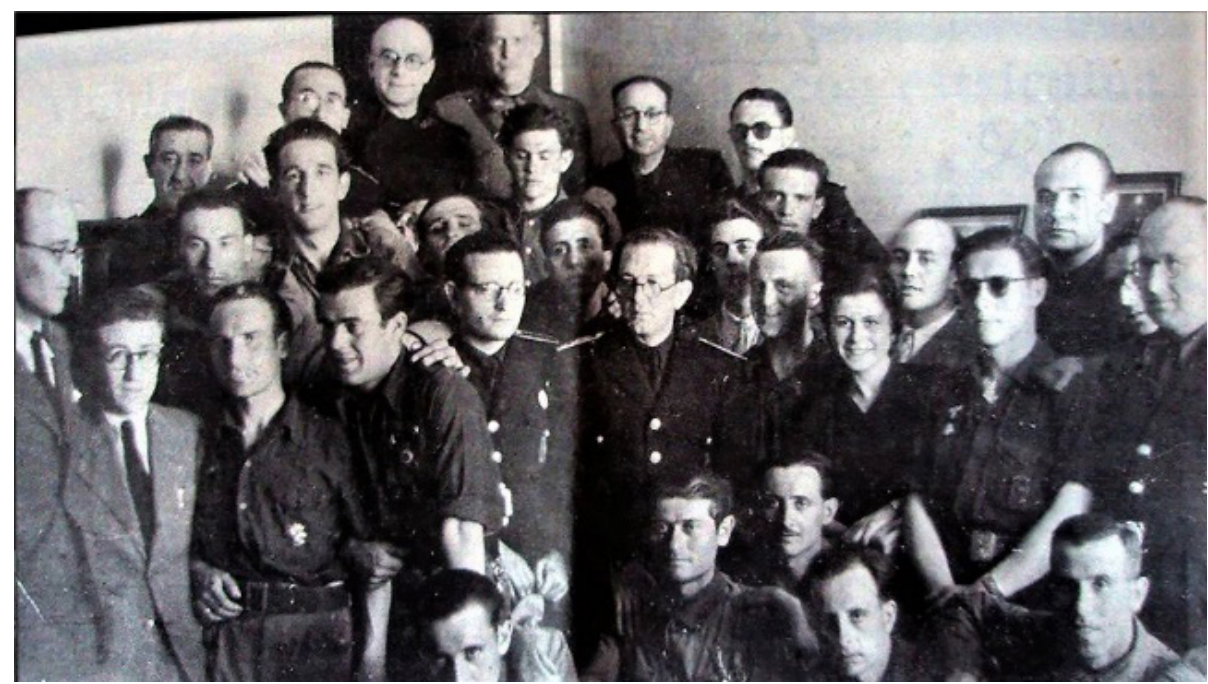

Recepción a los divisionarios por Laporta Girón y otros cargos del Movimiento (como se puede ver, hay más jefes que indios)

Un contingente más, de 21 voluntarios de toda la provincia, aunque la mayoría son de la capital, regresó el 6 de julio: José Manuel Rodríguez, Rafael Prieto, Francisco Carrilero, Juan López, Joaquín Escrivá, Enrique Paz Navío, Pedro Pérez Peral, Pedro Sáinz de Baranda, Juan Ortuño, Pedro Orovigt, Paulino Biosca, Jesús Cerro y Antonio Alarcón. Pocos días después (se puede ver la lista en el diario Albacete del 14 de julio) llegan Carlos Belmonte, Camilo Belmonte, José Joaquín Galdámez, Cándido Moreno, Enrique Alonso, Rafael Ros, Francisco Cantos, Francisco Gandía, Eliecer Ochando y Antonio Navarro, junto a Alonso Griñán, y otros, que es de creer sean de la provincia, porque van al final y no figuran en la orla. El 16 de agosto se habla de la llegada de Otoniel Ramírez -no Ramírez de Lucas, que estaba en el exilio, sino Ramírez Lara- y Ricardo Fernández Gutiérrez, con José Panadero, Antonio Ortuño, Jesús Sánchez, Rafael García Cuesta, Antonio Dueñas, José María González Miranda, y otros tantos de diferentes pueblos. Y aún seguirán llegando nuevos pequeños grupos: el 13 de diciembre se habla de la entusiasta acogida a Saturnino Cuevas, Rafael Ruiz, Francisco Navarro Vergara, Manuel Jarque, Francisco Honrubia y José González López. 
Por entonces, y acaso desde junio, puesto que los caídos conocidos en julio no figuran en ella, ya debía de estar confeccionada la orla, en la que puede haber errores burocráticos (nos dicen que hay algunos que no pisaron Rusia), aunque la mayoría de los nombres y fotos son bastante correctos. Son 120 hombres, más o menos los mismos que aparecen en la de Valladolid, ciudad mucho más grande y con mayor tradición falangista; más que en la de Toledo (aunque esta no dice que se trate solo de la ciudad), y más que la de Asturias, que no llega a 90. Se ha dicho que Albacete dio más divisionarios que otras muchas provincias, lo cual se ha atribuido a los padecimientos bajo el «dominio rojo», o al hecho de que muchos no habían combatido durante la contienda o lo hicieron en campo equivocado, por lo que ahora tenían que demostrar su apoyo al régimen franquista. Pero lo llamativo, como ya queda dicho, es que faltan algunos de los más conocidos, como Luis Martínez de la Ossa, Carlos Belmonte y Gonzalo Botija, que serían después alcaldes de Albacete. Una ausencia que solo se podría explicar porque se autoexcluyeran, por modestia o por no querer significarse mucho (difícil de creer, viendo sus biografías), o fueran excluidos por alguna razón, lo que a su vez plantea otros interrogantes:

¿Qué tienen en común Martínez de la Ossa y Gonzalo Botija? Un pasado izquierdista durante la República y la Guerra Civil, cuando el primero había militado en la FUE y fue teniente médico de una Brigada Mixta (en la que Gómez Flores dice que coincidió con Otoniel Ramírez -de Lucas, que no Lara- y con José Vergara), y el segundo formó parte del grupo de letrados de izquierdas que exigió al Frente Popular el cese de la Junta del Colegio de Abogados, a la que relevó, en agosto de 1936. Los hermanos Belmonte, como ya señalamos, tenían un pasado mucho más «presentable» desde el punto de vista falangista, pero formaban parte de una «buena familia» y además eran hijos del médico oftalmólogo don Nicolás Belmonte, líder de Acción Republicana, el partido de Azaña. Y aunque todos se habían afiliado a Falange, y alistado después para ir a Rusia, también podían ser considerados miembros de aquella burguesía denostada 
por los más radicales falangistas como José de Luna, ahora delegado del Frente de Juventudes. Como no me convence la idea de que falten por haberse alistado en las provincias de las que eran nativos, porque llevaban muchos años en Albacete, no encuentro otra razón, salvo el veto político, para justificar su ausencia en una orla que se hace -recordemos- en el 42.

Con todo, hay otros nombres que faltan en la orla, por lo que no sería prudente asegurar que Martínez de la Ossa, Botija y los Belmonte hayan sido excluidos contra su voluntad. También pudiera ser simple casualidad, aunque parece mucha casualidad la ausencia de tres nombres tan significativos, que además ostentaron cargos en Sindicatos o en el Ayuntamiento y la Diputación en los años cincuenta y sesenta, cuando además nos dicen que eran muy apreciados dentro de la Hermandad. Pero hay que advertir que ya por estas fechas -de los años cincuenta en adelante- los excesos verbales de la Falange antigua y la «revolución pendiente» se habían diluido dentro de aquel engendro llamado Movimiento, donde cabía todo lo que no discrepara. En plena Guerra Fría, ni Franco, convertido en amigo vergonzante de los americanos, ni España, que iniciaba la recuperación tras la oscura posguerra, ni los supervivientes de la DEV, cada vez más ajenos al poder y menos falangistas, eran ya los aliados de la Alemania nazi de los años cuarenta. Y en los divisionarios -bastantes de los cuales estaban colocados gracias a las ventajas que esta condición les había ofrecido- primaban mucho más los lazos de hermandad que las posibles diferencias políticas.

Más rara todavía es la ausencia en la orla de Remigio Martínez Espinosa, un ultraderechista sin la menor sospecha. Aunque no sea cierto lo que dice su hermana en El País de 7 de abril de 2006 sobre el alistamiento de sus cuatro hermanos, que la obligó a quedarse a cuidar del negocio familiar (solo hemos sabido de Remigio y de Luis García Sípido, que será su marido), la familia tenía todas las condiciones para ser respetada entre los vencedores de la Guerra Civil: su tienda fue asaltada y destrozada en marzo de 1936 y Remigio y su padre, secretario de Acción Popular durante la República, 
salieron a apoyar a la Guardia Civil en el golpe de julio de ese año, armados de escopetas, deteniendo a supuestos izquierdistas, lo que les llevaría a los dos a la cárcel (Tita cuenta que ella colocó la bandera bicolor que cosió mientras tanto, en día que los dos salieron de prisión a raíz de la entrada en Albacete de las tropas fascistas, que sería el 29 de marzo de 1939). Es de creer que entonces Remigio se afilió a Falange Española, y él mismo, al prologar la recopilación de crónicas de Sánchez Carrilero, cuenta cómo los dos lanzaron por la radio, en el 41, la primera proclama animando a los jóvenes a unirse a la aventura azul. Por lo tanto, en principio no cabe, en este caso, pensar que su omisión se debiera a cualquier antecedente «rojo». Otro misterio más, que tendrá que aclarar quien pueda y sepa.

Pero ya para entonces, con las nuevas que traían los expedicionarios repatriados, los voluntarios iban siendo cada vez menos, hasta el punto de no cubrirse las vacantes, como ha señalado Rodríguez Jiménez al respecto, a pesar del decreto que igualaba en ventajas a los divisionarios con los excombatientes de la Guerra Civil -que ocupaban ya muchas de las plazas vacantes en la Administración- y de la elevación de la presión social sobre los remolones. En Albacete aún se alistaron algunos voluntarios auténticos, que no pudieron ir en la primera tanda, pero es de suponer que tampoco faltaran, como ocurre en el resto del país, soldados de reemplazo que querían acortar su servicio militar y hacer méritos (mucho más numerosos de lo que se supone, según cifras del autor mencionado), «voluntarios forzosos», e incluso castigados, como podremos ver por los escritos del general Esteban en el 43. Ni los que pretendían huir de la justicia, como muestran después varias requisitorias judiciales publicadas contra cuatro de ellos en el Boletín Oficial de la Provincia de Albacete.

Mientras tanto, el 13 de octubre el diario Albacete comenzaba con un comunicado del Cuartel General del Führer, titulando: «La División Azul machaca al Comunismo», en alusión a un contraataque en el Cáucaso. Pero la mayoría de los divisionarios ya están en sus hogares, aunque algunos no han vuelto: el 29 de octubre, en un 
acto solemne, ante el monumento del parque a los Caídos de la Guerra Civil, a los que ahora se añade los de la División, Ramón Laporta impone a la madre de José González López la Cruz de Hierro enviada por las autoridades alemanas junto con unas cuantas paletadas de tierra de las tumbas de otros, que se habían colocado sobre un pedestal con la bandera de la esvástica nazi en una caja de "plata» (más bien parece zinc), desde el cual pasarían a otro con las de España y Falange Española. Todo ello en presencia de las autoridades, una guardia de honor divisionaria, la esposa de Laporta y las madres del citado González, Luis Badía y Ricardo Acebal, los primeros caídos, que pusieron las coronas de flores y dejaron la caja al pie del monumento, donde se encontraría muchos años después.

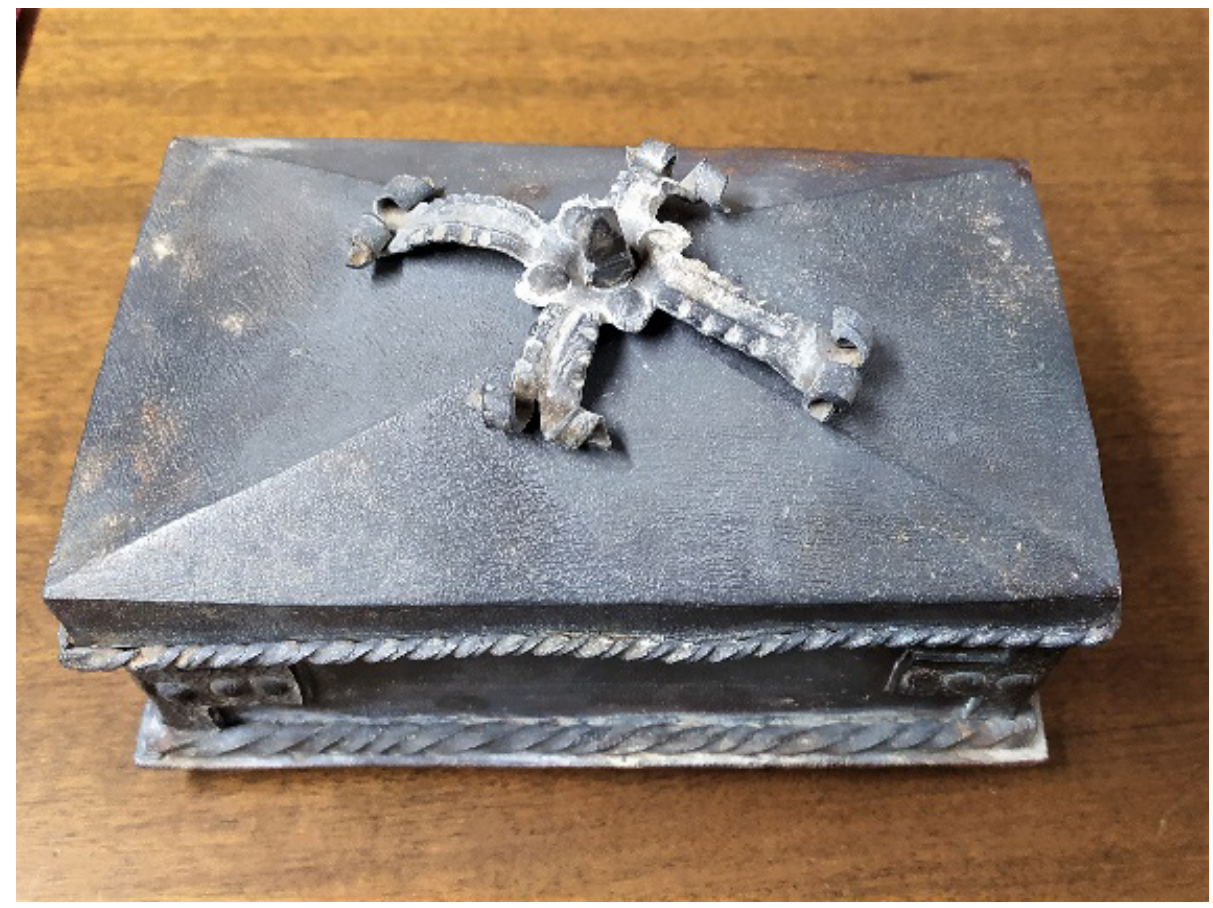

Caja de plata o zinc con tierra de las tumbas de los divisionarios. 


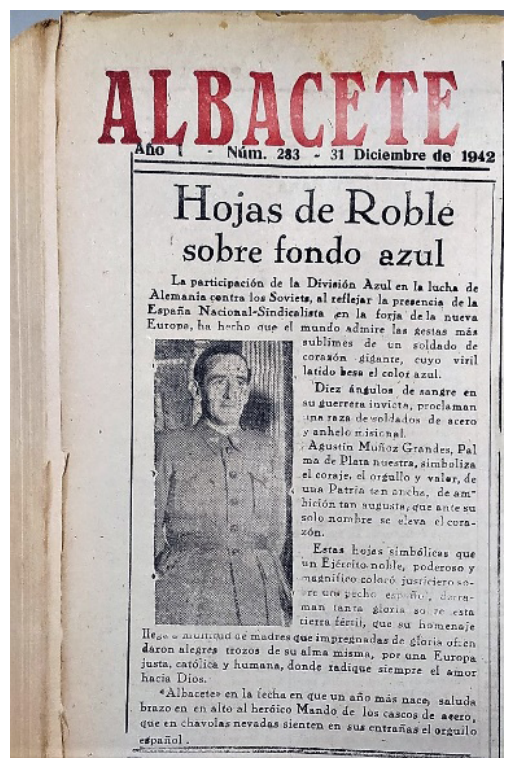

\section{CETE}
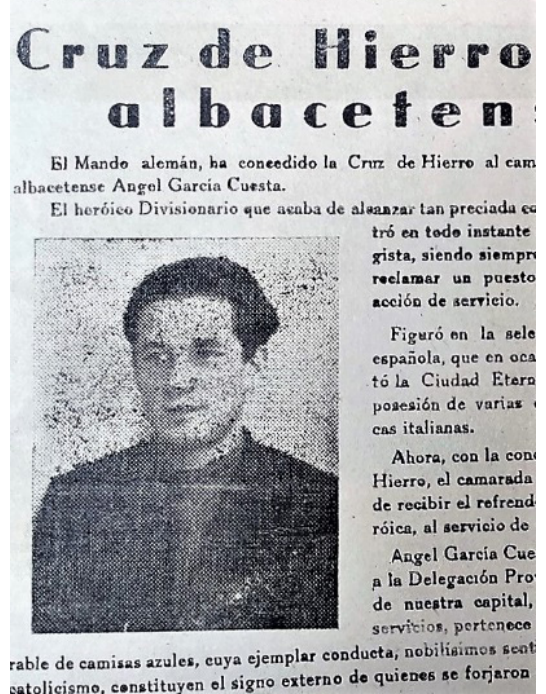

Noticias en el diario Albacete sobre la concesión de condecoraciones a Muñoz Grandes y al albacetense Ángel García Cuesta.

Pero, aunque todavía hubiera albacetenses combatiendo contra la Unión Soviética, para la mayoría la aventura se había terminado. El relevo en el mando de Agustín Muñoz Grandes -al que el diario Albacete del día 31 de diciembre dedica sus elogios tras ser condecorado por Hitler en persona con las hojas de roble sobre la Cruz de Hierro- era todo un indicio de que la guerra no iba como la propaganda se empeñaba en decir. Durante los primeros meses del nuevo año 43 el citado periódico recuerda todavía esporádicamente alguna expedición que va o vuelve del frente durante el mes de marzo, y refiere noticias triunfalistas sobre las actuaciones de los que allí quedaron (el 3 de abril da cuenta de que se ha concedido la Cruz de Hierro a Ángel García Cuesta, otro albacetense del segundo relevo, del que no conocemos muchos nombres).

También podremos ver en el diario Albacete la crónica y la foto del último homenaje que se rinde a las madres de los muertos y la de un cementerio español en aquellas lejanas latitudes, donde los «voluntarios» caían como moscas. Solo el «miércoles negro», 10 de febrero de 1943, en Krasni Bor, la División perdió 2.500 hombres 
entre muertos, heridos y desaparecidos (el famoso capitán Oroquieta calcula en un $90 \%$ las bajas de sus fuerzas); y es de suponer que algunos de estos muertos y desaparecidos fueran albacetenses, pero ni sobre ellos, ni de los que cayeron en los meses siguientes, tenemos más noticias que la de un funeral, el 10 de agosto, por las almas de Ángel Carrión Martínez, Dacio Robles, y José Hidalgo Gil, fallecidos los dos primeros en los meses de mayo y junio. Por supuesto, tampoco las hay de desertores, ni de los prisioneros, de los cuales Fulgencio García, Luis López, Telesforo Moreno y José Martínez García, junto con otros tres de diferentes pueblos, regresaron en el 54, a bordo del Semíramis, tras pasar once o doce años de cautiverio, cuando la mayoría de alemanes, rumanos e Italianos regresaron en cinco. Silencio que contrasta con las demostraciones del verano anterior y que puede atribuirse a que no fueran hijos de las buenas familias, a que los falangistas no los reconocieran, o a que solo nombrar su participación al lado de nazis, y encima en una guerra que se estaba perdiendo, ya resultara incómodo.

Además, por entonces los voluntarios eran baste más escasos. Por más que algunos digan que no se hicieron levas más o menos forzosas, el general Esteban Infantes, sucesor en el mando de Agustín Muñoz Grandes, protesta por la baja calidad de los nuevos reclutas, a menudo forzados e «indeseables», por su mala conducta e intenciones, que están llegando a Rusia, y que pueden pasarse al enemigo (como, por otra parte, parece que temía ya unos meses antes el Estado Mayor), y en mayo manifiesta que la DEV no se puede convertir en un cuerpo disciplinario al que los hombres van solo como castigo, como dice Rodríguez Jiménez en su artículo. Claro, que nada de esto puede leerse aún en el diario Albacete, que habla siempre de avances y victorias germanas en el frente del Este o en el norte de África e Italia (a lo sumo, de «tácticas de repliegue», en vez de retiradas), al tiempo que jalea al «invencible» ejército nipón y da alguna noticia sobre hazañas heroicas de los divisionarios, que van disminuyendo conforme van cambiando las tornas de la guerra y empiezan a llegar las de los bombardeos sobre Berlín y Bremen. 
También encontraremos, aunque de tarde en tarde, las de los funerales por los nuevos caídos -pocos, y más discretos- o sobre la llegada, en el segundo semestre de este año, de nuevos contingentes repatriados de Rusia, que reciben a veces homenajes en Irún, San Sebastián, Valladolid o Burgos, pero no en Albacete, que se sepa. Eso sí, encontraremos cada vez más noticias sobre actos cívico-religiosos, como la exaltación y entronización del Sagrado Corazón de Jesús, en la Delegación de Sindicatos, y misas de Campaña presididas por las autoridades en línea con la imagen del nacional-catolicismo que imponía el discurso de Luis Arrese, que el 8 de septiembre de 1943 dice en Burgos que España no solamente ya no es totalitaria, sino que su destino «es unir al mundo en una norma espiritual y católica». Tiene gracia, viniendo de la misma persona que había dado a la DEV ese nombre de «Azul».
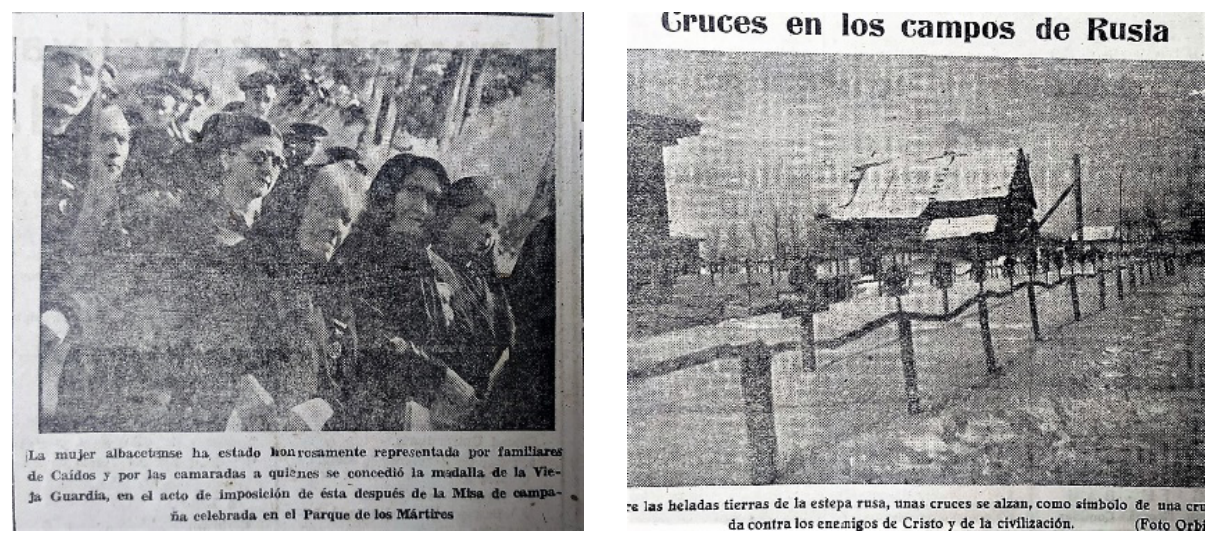

Madres de Caídos condecoradas en Albacete.

Un cementerio en Rusia. Imágenes del diario Albacete

Cuando, con las presiones de los anglosajones y el cambio de cariz de la Guerra Mundial, España se declara neutral, en lugar de «no beligerante» (que son cosas distintas), y es cesado Ramón Serrano Suñer, la División será retirada del frente (solo permanecieron algunos filonazis en la Legión Azul, en la que no sabemos si hubo albacetenses). Pronto darán comienzo la «desfascistización» del régimen franquista y la relegación de los divisionarios, en parangón, al menos, con los excombatientes y excautivos de la Guerra Ci- 
vil, mucho mejor tratados, como han señalado Alcalde y Rodríguez. La División Azul era un espejo incómodo que ofrecía la imagen del Estado fascista y germanófilo que la hizo nacer, y ya empezaba a ser lo que luego sería, «la memoria amarga de los perdedores dentro del bando de los vencedores; es decir, la de aquellos sectores del régimen franquista que fracasaron en su intento de hacer una España auténticamente fascista», como ha señalado Núñez Seixas. Si en su día sirvió para pagar a Hitler sus apoyos de 1936-39 y aprovechar sus triunfos en la Guerra Mundial, ahora, su retirada servirá de moneda de cambio para aplacar a Roosevelt, Churchill y sus aliados, y evitar la invasión, o que Franco se viera detenido, igual que Mussolini en aquel mes de julio, o juzgado después en algún juicio semejante al de Nuremberg. Poco a poco, y en grupos numerosos, irían regresando muchos divisionarios, que a veces son objeto de homenajes en Irún, San Sebastián, Valladolid o Burgos, pero después se pierden de manera discreta -y opaca- en sus provincias, de forma que hoy en día no sabemos siquiera quiénes y cuantos fueron los últimos paisanos que lucharon en Rusia.

Obviamente, los ricos «reptiles» aludidos por Luna Cañizares recobrarán muy pronto, si es que alguna vez dejaron de tenerlo, el control económico efectivo de las instituciones, valiéndose a menudo de exdivisionarios obedientes al Jefe del Estado, como fueron Martínez de la Ossa, Belmonte o Botija, precisamente tres que faltan en la orla, que ostentan la alcaldía en los años cincuenta y sesenta, pero sin irritar a los «poderes fácticos», aunque es cierto que los terratenientes lo perdieron en parte, con el desarrollismo, que no por exigencias del régimen franquista. Muchos divisionarios tuvieron que sentirse defraudados, incluso utilizados, por la turbia política del régimen, que los había usado de carne de cañón y ahora comenzaba a volverles la espalda (el ministro Arrese, que había visitado Albacete este año y rendido homenaje a los caídos y a los divisionarios, ordenaba a los jefes provinciales olvidarse del totalitarismo y volcarse «en la paz y el trabajo», lo que provocará protestas falangistas). Pero la mayoría se aclimató muy pronto a esta paz 
silenciosa, ejerciendo cada uno su carrera -sobre todo, abogados, médicos y docentes, aunque estos parecen preferir buscarse otro trabajo- o acomodándose, los que no la tenían, en la Administración, la prensa y la radio, la política o el sindicalismo, que tan solo exigían una obediencia ciega. Aquellos entusiastas muchachos que enviaban crónicas desde Rusia dejarán no ya solo de escribirlas, sino de recordar su paso por la guerra, más allá de las misas por los muertos y el encuentro nostálgico con viejos camaradas, reviviendo sucesos, que se embellecerán con el paso del tiempo, como el de la campana que tres albacetenses trajeron a la Virgen de los Llanos tras haberla sacado de un templo destruido..., que era una cabaña de madera respetada por el fuego artillero en la inicial versión de Sánchez Carrilero. Una hermosa manera, en todo caso, de encubrir un expolio, bien es verdad que no de la categoría de la «caza de iconos» y obras de arte dignas de estar en un museo, que Juan Eugenio Blanco reconoce solían practicar muchos divisionarios,

De los que todavía seguían combatiendo solo llegan noticias a través del Servicio de Mensajes, como las recibidas de Ángel García Cuesta y de Antonio Andújar, que en la prensa local del 20 de septiembre comunican que están bien de salud y mandan sus recuerdos a sus chicas y a toda su familia. Andújar, que además sería redactor de la Hoja de Campaña de la DEV, publica en el periódico Albacete, en esa misma fecha, un artículo titulado «Los novios de la muerte»; pero ya no hay noticias de otras crónicas enviadas entonces desde el frente. Entre los retornados, Juan Ramírez de Lucas escribirá en el mismo con cierta asiduidad sobre las nuevas salas del Museo del Prado, o sobre la primera bandera nacional, o sobre artesanía; asuntos todos ellos ajenos a la guerra, aunque no sin ribetes de anticomunismo patriótico y fascista. Con mayor compromiso, Rafael Prieto lo hace sobre los camaradas que siguen combatiendo, y el rabioso José de Luna Cañizares se despacha de nuevo, a su manera, el 28 de junio y el 8 de noviembre, contra «las gentes de alma contrahecha y pequeña» que esperan que termine la lucha arrellanados en su comodidad, diciéndoles que «hemos hecho la guerra 
para evitar que la horda roja le volviera a quitar a usted el puro de la boca y el periódico extendido en la mesa del café cuando todavía se frota idiotamente las manos...,» y advierte «que a nosotros, que les hemos defendido sus privilegios, no se nos oculta su actitud, y sepa que le señalaremos como marxista embrionario que es español porque no ha podido o no ha pensado ser otra cosa...»Y denuncia que hay liberales, masones y traidores vendidos, que pretenden aguar a la Falange con pretexto de la unidad de acción, y a los que hay que barrer.

En realidad, los cantos a la revolución nacional-sindicalista y las execraciones a los acomodados, masones y traidores, eran solo desahogos e Ilusiones. En la España de Franco solamente cabían dos ideas: la de él, consistente en tener el poder a toda costa, con las metamorfosis que fueran necesarias, y la otra, que englobaba a todas las demás, azules, rojas o de cualquier color, que estaban destinadas al silencio y la cárcel, sobre todo las últimas, pero no en exclusiva (recordemos a Hedilla y a Merino). Aún quedaban algunos falangistas ilusos que pensaban en la revolución nacional-sindicalista, pero Arrese, ministro secretario, que expulsó del partido y de los sindicatos a Merino y a otros 4.000 discrepantes, y Laporta, su hombre en Albacete, habían comprendido las reglas del sistema: obedecer al jefe y mantener el difícil equilibrio entre las fuerzas que apoyaban al régimen dentro de la provincia: el Ejército, el clero, la Falange, los tradicionalistas $\mathrm{y}$ los terratenientes y caciques de siempre, y animar a los jóvenes a luchar por la patria, o a dejar de

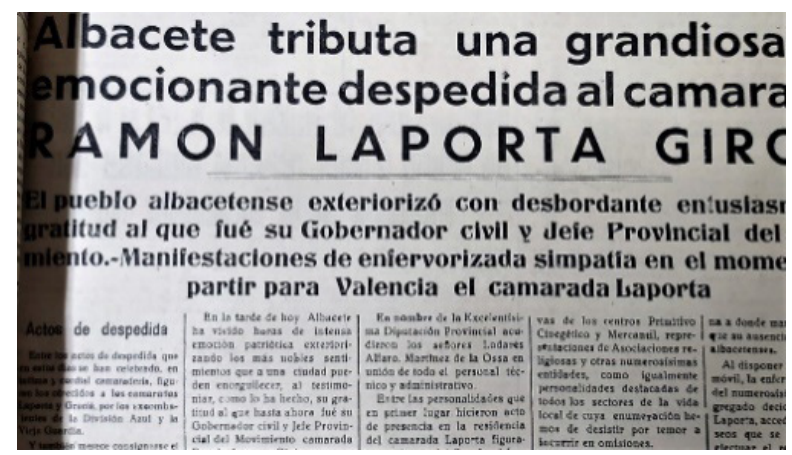
hacerlo cuando fuera oportuno. Poco tiempo después, Laporta, fue ascendido al Gobierno Civil de Valencia, mucho más importante, sin duda en recompensa, entre otros servicios, por la sangre derramada 
-por otros- en la nieve de Rusia. Se comprende que fuera despedido con «intensa emoción...», «desbordante entusiasmo...» y manifestaciones de «enfervorizada simpatía» como dice el periódico Albacete del 15 de abril de 1943.

Con Rodríguez Acosta, nuevo gobernador, que lo será por más de quince años, pocos pensaban ya en la «revolución». Hasta el irreductible De Luna Cañizares se dejará querer y pasará de la Delegación del Frente de Juventudes a concejal nombrado «por el tercio del dedo» en el 48, junto a Carlos Belmonte y Sánchez Carrilero, y alcalde accidental, en el 49-50, a la Delegación Provincial de Cultura Popular (con función de censor de cines y espectáculos), y a presentar poemas a los juegos florales de Tobarra, provocando, por cierto, un buen escándalo por la parcialidad del jurado hacia él, y en los años sesenta y setenta a las de Información y Turismo en Albacete y Murcia. Destinos, todos ellos, mejores que la escuela que había abandonado en el 41. Y es que en aquellos tiempos de silencio interior y Guerra Fría nada era lo mismo, salvo el poder omnímodo del Caudillo de España, que ya no era el aliado de los totalitarios Hitler y Mussolini contra las «democracias plutocráticas», sino el providencial introductor de un modelo distinto de representación -su «Democracia Orgánica»- y el lúcido profeta que venció al comunismo y salvó la civilización, el «Timonel de la Dulce sonrisa» y «Centinela de Occidente...» Y amigo vergonzante de los americanos, a los que llegaría a ofrecer el envío de tropas a Corea, es de creer que en defensa del mundo occidental e incluso permitió la instalación de bases en el suelo español. En nuestra capital, más allá de reuniones y nostálgicas misas de campaña en octubre, a veces presididas por las autoridades, ante uno de los pocos monumentos que se le dedicaron en España, diseñado, por cierto, por Belmonte, antes de ser alcalde, la División Azul estaba arrinconada, cuando no marginada, pese a las apariencias, por el poder político. 


\section{REFERENCIAS BIBLIOGRÁFICAS.}

ALCALDE FERNÁNDEZ, Ángel (2012) Cultura de Guerra y excombatientes para la implantación del franquismo en Albacete. Al-Basit (57), pp. 39-69.

BLANCO, Juan Eugenio. (1954) Rusia no es cuestión de un dia... Publicaciones Españolas.

GÓMEZ FLORES, Andrés. (2015) Los años sombríos: Albacete durante el franquismo. Altabán.

MARTÍNEZ ESPINOSA, Encarnita (Tita). (1976). Vivir, sencillamente. Albacete.

NÚÑEZ SEIXAS, Xosé Manuel. (2005) Los vencedores vencidos: la peculiar memoria de la División Azul. Pasado y Memoria. Revista de Historia Contemporánea (4), 83-113. http://hdl. handle.net/10045/5546

SÁNCHEZ CARRILERO, Javier. (1992) Crónicas de la División Azul. Gráficas Albacete.

RODRÍGUEZ JIMÉNEZ, JOSÉ LUIS (2007). De héroes a indeseables. La División Azul. Espasa.

RODRÍGUEZ JIMÉNEZ, J. L. (2012). La contribución de la División Española de Voluntarios a la invasión de la URSS. Cuadernos de Historia Contemporánea (34), 91-18.

RODRÍGUEZ JIMÉNEZ, J. L. (2009). Ni División Azul, ni División Española de Voluntarios: el personal forzado en el cuerpo expedicionario enviado por Franco a la URSS. Cuadernos de Historia Contemporánea (31), 265-296.

PRESTON, P. (1993). Franco «Caudillo de España». Grijalbo.

SUÁREZ FERNÁNDEZ, L. (1984). Francisco Franco y su tiempo. (II), Azor, Estudios Contemporáneos. 